\title{
Pseudocyst in the Pancreatic
} Tail Associated with Chronic Pancreatitis Successfully Treated by Transpapillary Cyst Drainage

\author{
Itaru Naitoh ${ }^{\mathrm{a}}$ Hirotaka Ohara $^{\mathrm{a}}$ Yasutaka Okayama $^{\mathrm{b}}$ \\ Takahiro Nakazawa $^{a}$ Tomoaki Ando ${ }^{a}$ Kazuki Hayashi ${ }^{a}$ \\ Fumihiro Okumura $^{a}$ Yasuhiro Kitajima ${ }^{b}$ Tessin Ban $^{b}$ \\ Katsuyuki Miyabe ${ }^{b}$ Koichiro Ueno ${ }^{b}$ Takashi Joh $^{a}$ \\ Hitoshi Sano ${ }^{b}$ \\ aDepartment of Gastroenterology and Metabolism, Nagoya City University \\ Graduate School of Medical Sciences, Nagoya, and ${ }^{\text {bDepartment }}$ of \\ Gastroenterology, Gifu Prefectural Tajimi Hospital, Tajimi, Japan
}

\section{Key Words}

Pancreatic pseudocyst - Transpapillary drainage $\cdot$ Pancreatic cyst drainage $\cdot$ Pancreatic duct drainage $\cdot$ Pancreatic stent $\cdot$ Nasocystic catheter

\begin{abstract}
We report a 50-year-old male with pseudocysts in the pancreatic tail associated with chronic pancreatitis successfully treated by transpapillary cyst drainage. He had previously undergone ultrasonography-guided percutaneous cyst drainage for a pancreatic pseudocyst in our hospital. He was readmitted due to abdominal pain and fever. Computed tomography showed recurrence of a pseudocyst in the pancreatic tail measuring $5 \mathrm{~cm}$ in diameter. Since conservative treatment failed, endoscopic retrograde pancreatography was performed. There was communication between the pseudocyst and the main pancreatic duct, and pancreatic duct stenosis proximal to the pseudocyst. First, transpapillary pancreatic duct drainage was performed using a plastic stent, but the pseudocyst did not decrease in size and became infected. After removal of the stent, a pigtail type nasocystic catheter was placed in the pseudocyst via the pancreatic duct. The pseudocyst infection immediately disappeared, and the pseudocyst gradually decreased and disappeared. After removal of the nasocystic catheter, no recurrence was observed. As transpapillary drainage of pancreatic pseudocyst, cyst drainage and pancreatic duct drainage have been reported. In our patient with pseudocyst in the
\end{abstract}


pancreatic tail, duct drainage was ineffective and the pseudocyst was infected, whereas cyst drainage was very effective. We considered that cyst drainage by a nasocystic catheter was the first-line therapy as the transpapillary drainage of the pancreatic pseudocyst.

\section{Introduction}

Pancreatic cysts are classified into pseudocysts, cystic tumors and true cysts. The majority of pancreatic cysts are pseudocysts. Most cystic tumors consist of serous cystic tumors, mucinous cystic neoplasms, intraductal papillary mucinous neoplasms and solid pseudopapillary tumors. Pancreatic cystic tumors represent a wide clinicopathological spectrum from benign to malignant. Mucinous cystic neoplasms and intraductal papillary mucinous neoplasms are precursor lesions of pancreatic adenocarcinoma [1]. Symptomatic cysts, increasing age and multilocular cysts (with a solid component and thick walls) are predictors of malignancy [2], whereas pseudocysts occur following acute pancreatitis, chronic pancreatitis or secondary to pancreatic trauma and have no malignant potential. Pseudocysts can resolve spontaneously or cause persistent symptoms and complications. The complications of pseudocysts are infection, obstructive jaundice, intracystic bleeding, hematoma and rupture. A diameter of $>6 \mathrm{~cm}$ and growth of the pseudocysts are important predictors of the need for treatment [3].

For the treatment of pseudocysts, endoscopic drainage instead of surgical or percutaneous drainage is frequently performed. As endoscopic drainage, transpapillary drainage and transmural drainage, such as cystogastrostomy and cystoduodenostomy, have been reported. An appropriate drainage is selected based on anatomical characteristics. Yet recently, transpapillary drainage without needle puncture has been recommended because of low complication rate [4]. As transpapillary drainage, cyst drainage, in which the stent is inserted into the cyst, and duct drainage, in which the stent is placed in the pancreatic duct, have been reported, but their indications have not yet been established. As stents, the endoprosthesis is generally used, but the nasocystic catheter is also used in some cases [5].

We report a patient with a pseudocyst in the pancreatic tail successfully treated by transpapillary cyst drainage with a nasocystic catheter.

\section{Case Report}

A 50-year-old male with a 25-year history of alcohol abuse was admitted to our hospital due to epigastric pain and fever. He had undergone ultrasonography (US)-guided percutaneous cyst drainage for a pseudocyst associated with chronic pancreatitis 3 months earlier, and the pseudocyst had disappeared. His temperature was $39.2^{\circ} \mathrm{C}$, and tenderness was present in the left hypochondrium. Blood data indicated an increased value in AST 65 IU/l, $\gamma$-GTP 339 IU/l, ALP 440 IU/l, CRP 22.6 mg/dl, and elastase $11,164 \mathrm{ng} / \mathrm{ml}$. US and computed tomography (CT) showed a large pseudocyst measuring $5 \mathrm{~cm}$ in diameter and some small cysts in the pancreatic tail (fig. 1). A heterogeneous echo was observed in US imaging. The pancreas was generally atrophic, and there were no pancreatic stones. Magnetic resonance cholangiopancreatography revealed a main pancreatic duct stenosis in the pancreatic body and cysts in the pancreatic tail.

Recurrence of the pseudocyst secondary to alcohol was diagnosed, and conservative treatment was performed for about 3 weeks. The abdominal pain and fever improved, and blood data normalized, but the pseudocyst did not decrease in size. Endoscopic retrograde pancreatography showed communication between the pseudocyst and the main pancreatic duct, and a main pancreatic duct stenosis proximal to the pseudocyst (ig. 2). First, a 5-Fr-sized plastic stent (Zimmon pancreatic stent; 
Wilson-Cook Medical Inc., Winston-Salem, N.C., USA) was placed beyond the stenosis. Transpapillary pancreatic duct drainage was performed for 2 weeks, but the pseudocyst increased, and infection occurred. After removal of the stent, a 5-Fr-sized pigtail type nasocystic catheter (Flexima ENBD catheter; Microvasive Endoscopy, Boston Scientific Corp., Natic, Mass., USA) was placed in the pseudocyst via the pancreatic duct (fig. 3). The drainage fluid from the pseudocyst was sticky debris. We irrigated the cystic cavity with saline solution from the endoscopic nasocystic catheter for 1 week.

After nasocystic drainage the symptoms improved immediately, and blood data were normal after 1 week. Since CT performed after 2 weeks revealed a marked reduction in the size of the pseudocyst, the catheter was kept for 2 weeks and then removed. After the removal, the cyst disappeared. Neither recurrence of pseudocysts nor symptoms have been observed after treatment.

\section{Discussion}

Pancreatic pseudocysts complicate mainly acute and chronic pancreatitis. Approximately $20-60 \%$ of pseudocysts regress spontaneously. The majority regress within 6-12 weeks. Symptomatic pseudocysts and pseudocysts without evidence of regression for longer than 6 weeks are generally an indication for drainage therapy. We abided by this indication. However, this case was not in this indication, as the patient had undergone US-guided percutaneous cyst drainage for the pseudocyst 3 months earlier and the pseudocyst had recurred. We considered that this pseudocyst might not have regressed. Therefore we performed drainage therapy.

Previously, surgical drainage was the only effective treatment for pancreatic pseudocysts, but several authors have reported significant procedural morbidity and mortality $[6,7]$. Subsequently, CT- or US-guided percutaneous drainage developed and has been reported to be useful. However, the problems of this drainage method were a high recurrence rate and a high incidence of fistula formation $[8,9]$.

Since the first endoscopic treatment for pseudocysts in 1975 [10], many studies have been reported with advances of endoscopes, devices and technique. As an endoscopic treatment, there are two approaches, i.e., transpapillary drainage and transmural drainage such as cystogastrostomy and cystoduodenostomy, and an appropriate method is selected based on the anatomical characteristics of the pseudocyst. Transpapillary drainage can be performed if the pseudocyst communicates with the main pancreatic duct, and transmural drainage if the pseudocyst is in direct contact with the gastric or duodenal wall. Previously, transmural drainage was performed irrespective of the presence or absence of cyst-duct communication, and a high pseudocyst disappearance rate (90-98\%) was reported. However, this technique is difficult, and the incidence of complications such as hemorrhage and perforation was relatively high [11]. Binmoeller et al. [4] performed endoscopic drainage in 53 patients with pseudocysts, of whom 33 underwent transpapillary drainage and the other 20 transmural drainage. The technical success rates were 100 and $80 \%$ for transpapillary and transmural drainage, respectively, and the pseudocyst disappearance rate was $94 \%$ for both methods. They reported that transpapillary drainage is less invasive and safe, recommending this method as the first choice. Based on previous reports, communication between the pseudocyst and main pancreatic duct is observed in $55-69 \%$ of patients $[4,7,12,13]$, and thus transpapillary drainage is indicated in a large proportion of patients with pseudocysts.

As transpapillary drainage, cyst drainage in which the stent is placed directly in the pseudocyst, and duct drainage in which the stent is placed in the main pancreatic duct near the cyst, have been reported. Barthet et al. [5] performed transpapillary drainage in 30 patients, of whom 12 could be treated by cyst drainage but the other 18 could not be treated by cyst drainage and underwent duct drainage. Since the pseudocyst 
disappearance rate was higher for cyst drainage (92\%) than duct drainage (67\%), they recommended that cyst drainage should be performed whenever possible. Catalano et al. [14] performed duct drainage beyond the main pancreatic duct stenosis proximal to the pseudocyst and observed cyst disappearance in $88 \%$, concluding that duct drainage should be selected in the presence of main pancreatic duct stenosis. Thus, there is no consensus concerning the placement site of the stent.

The location of pseudocysts affects the effect of transpapillary cyst drainage. Previous studies have reported a lower success rate in the pancreatic tail (60\%) than in the pancreatic head and body $(80 \%)[5,14]$. This may be due to technical difficulties in the area apart from the papilla.

Our patient showed communication between the pseudocyst and the main pancreatic duct accompanied by pancreatic duct stenosis. Therefore duct drainage was first performed, but the pseudocyst did not decrease in size. Next, the drainage method was changed to cyst drainage using a nasocystic catheter, which resulted in disappearance of pseudocyst. Barthet et al. [5] used a nasocystic catheter in cases with heterogeneous pseudocyst, i.e. with associated debris and necrotic tissue or pancreatic abscesses, to allow irrigation of the cystic cavity with saline solution. In our case, heterogeneous echo was observed in US imaging. The drainage fluid from the pseudocyst was sticky debris. The cyst content was one of the reasons why the pseudocyst did not regress with pancreatic stent insertion and became infected. Duct drainage is technically easier than cyst drainage, but we recommend cyst drainage by a nasocystic catheter as the first choice, especially when the cyst content is heterogeneous.

As complications of transpapillary drainage, acute pancreatitis, infection of the pseudocysts and pseudocyst biliary fistula have been reported. Kobayashi et al. [15] reported a case of chronic pancreatitis associated with infected pseudocysts after endoscopic pancreatic stenting. We should take this complication into consideration when performing transpapillary drainage, especially in cases of duct drainage with pancreatic stent.

We report a patient with a pseudocyst in the pancreatic tail successfully treated by transpapillary cyst drainage with a nasocystic catheter for a short period of time. This case may provide important information for the selection of two transpapillary drainage techniques in the future. 


\begin{tabular}{r|l|l|l} 
Case Reports in & $\begin{array}{l}\text { Case Rep Gastroenterol 2008;2:390-397 } \\
\text { D0I: 10.1159/000163377 }\end{array}$ & Published online: November 11, 2008 & $\begin{array}{l}\text { @ 2008 S. Karger AG, Basel } \\
\text { ISSN 1662-0631 } \\
\text { www.karger.com/crg }\end{array}$ \\
\hline
\end{tabular}

Fig. 1. CT showed a large pseudocyst measuring $5 \mathrm{~cm}$ in diameter and some small cysts in the pancreatic tail.

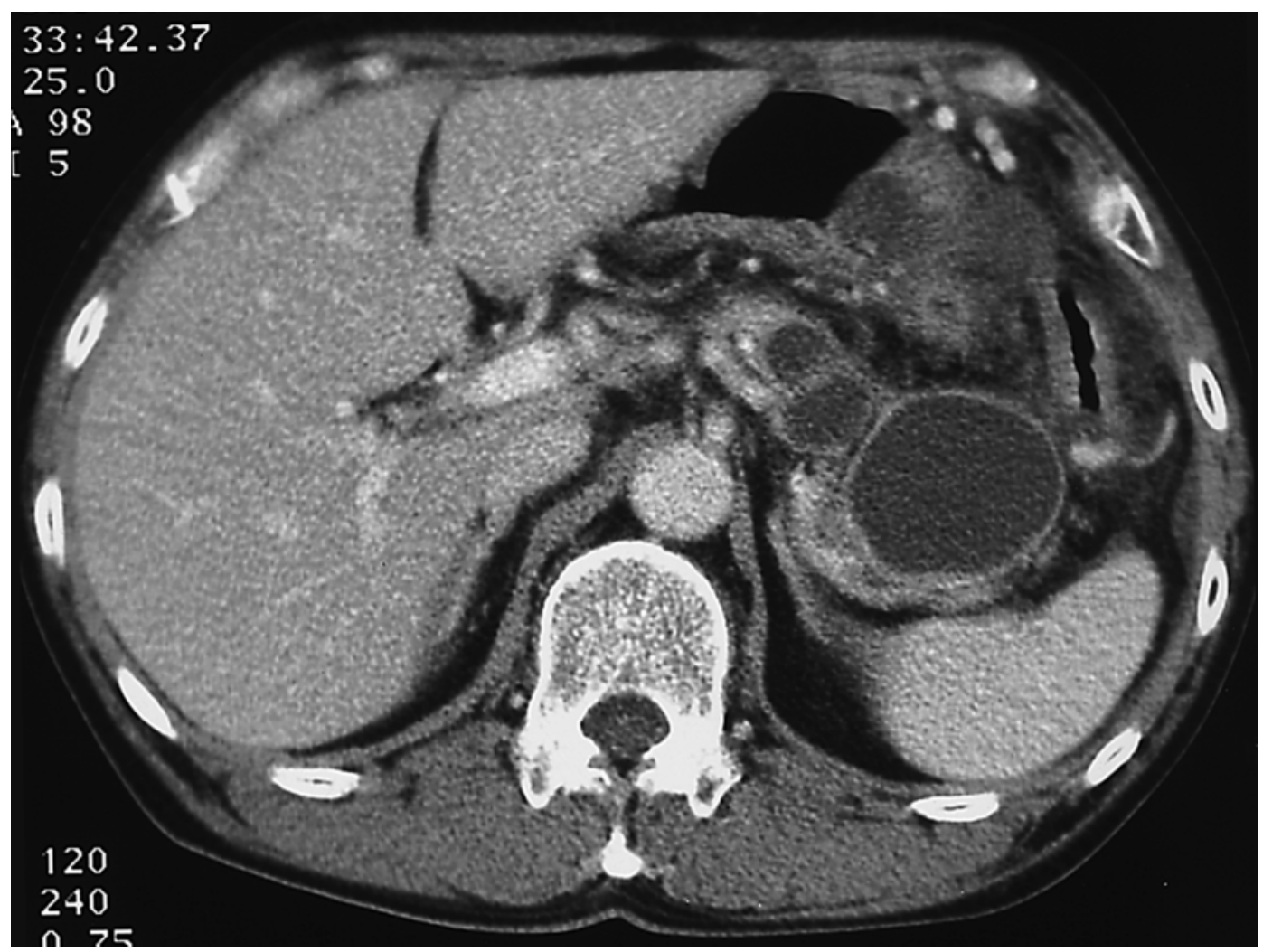




\begin{tabular}{r|l|l|l} 
Case Reports in & $\begin{array}{l}\text { Case Rep Gastroenterol 2008;2:390-397 } \\
\text { D0I: 10.1159/000163377 }\end{array}$ & Published online: November 11, 2008 & $\begin{array}{l}\text { O 2008 S. Karger AG, Basel } \\
\text { ISSN 1662-0631 } \\
\text { www.karger.com/crg }\end{array}$ \\
\hline
\end{tabular}

Fig. 2. Endoscopic retrograde pancreatography showed communication between the pseudocyst (arrows) and the main pancreatic duct, and a main pancreatic duct stenosis (arrowhead) proximal to the pseudocyst.

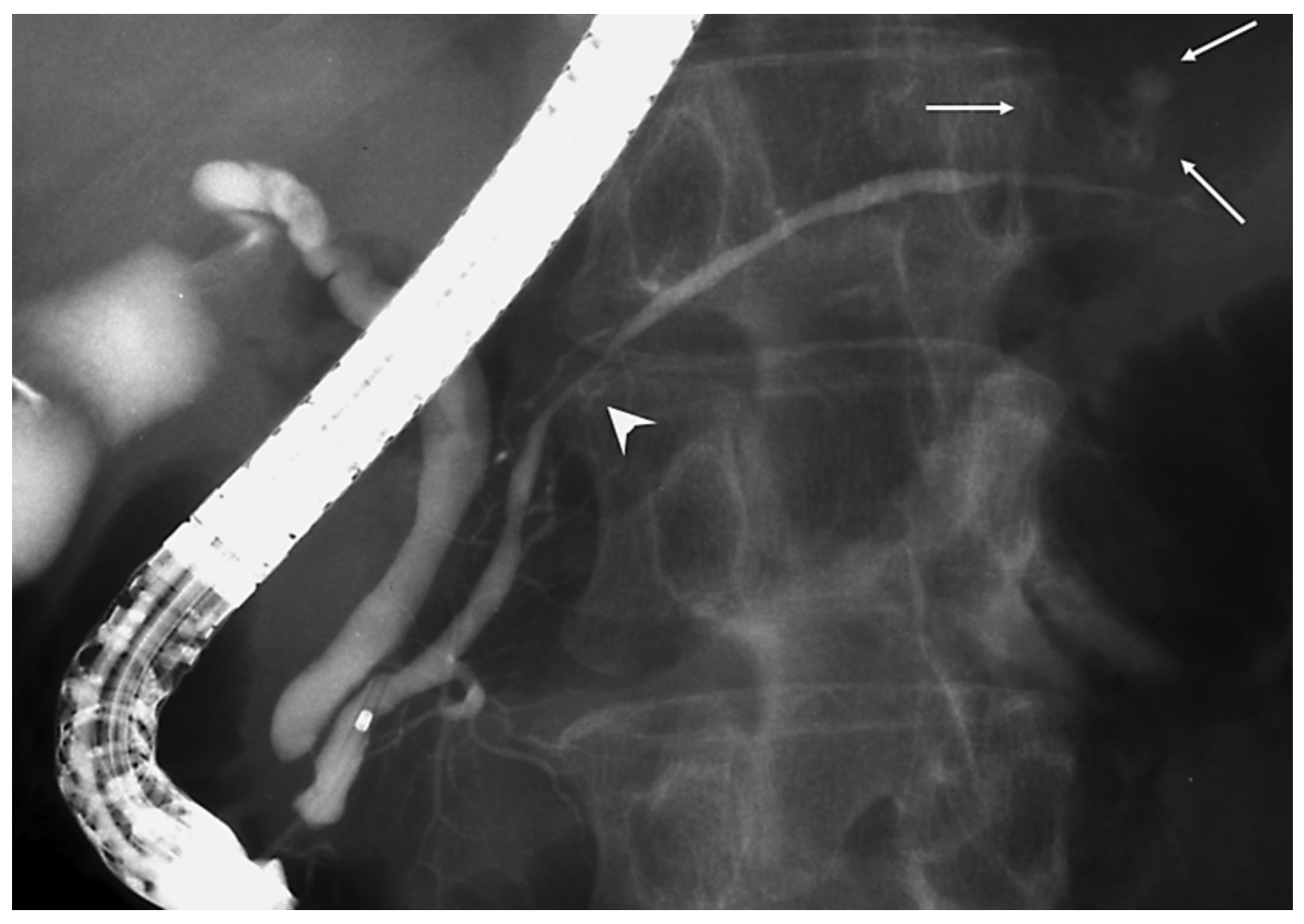




\begin{tabular}{r|l|l|l} 
Case Reports $/ \mathrm{h}$ & $\begin{array}{l}\text { Case Rep Gastroenterol 2008;2:390-397 } \\
\text { D0I: 10.1159/000163377 }\end{array}$ & Published online: November 11, 2008 & $\begin{array}{l}\text { O 2008 S. Karger AG, Basel } \\
\text { ISSN 1662-0631 } \\
\text { www.karger.com/crg }\end{array}$ \\
\hline
\end{tabular}

Fig. 3. A pigtail type nasocystic catheter was placed in the pseudocyst via the pancreatic duct.

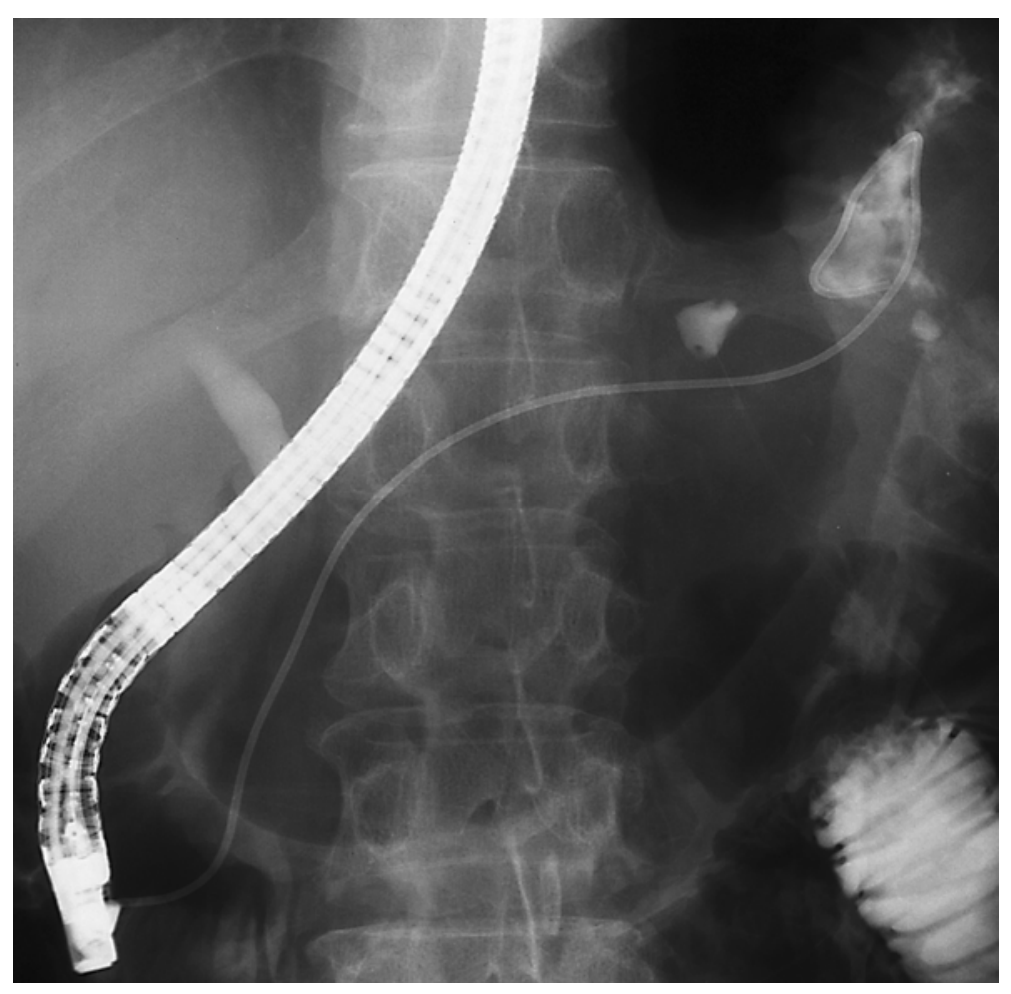




\section{References}

1 Singh M, Maitra A: Precursor lesions of pancreatic cancer: molecular pathology and clinical implications. Pancreatology 2007;7:9-19.

-2 Garcea G, Ong SL, Rajesh A, Neal CP, Pollard CA, Berry DP, Dennison AR: Cystic lesions of the pancreas. A diagnostic and management dilemma. Pancreatology 2008;8:236-251.

-3 Lu X, Uchida E, Yokoyama S, Nakamura Y, Amimoto T, Tajiri T: Features and choice of treatment of acute and chronic pancreatic pseudocysts - with special reference to invasive intervention. Pancreatology 2008;8:30-35.

-4 Binmoeller KF, Seifert H, Walter A, Soehendra N: Transpapillary and transmural drainage of pancreatic peudocyst. Gastrointest Endosc 1995;42:219-224.

-5 Barthet M, Sahel J, Bodiou-Bertei C, Bernard JP: Endoscopic transpapillary drainage of pancreatic pseudocysts. Gastrointest Endosc 1995;42:208-213.

-6 Martin EW Jr, Catalano P, Cooperman M, Hecht C, Carey LC: Surgical decision-making in the treatment of pancreatic pseudocysts. Internal versus external drainage. Am J Surg 1979;138:821-824.

7 Barkin JS, Hyder SA: Changing concepts in the management of pancreatic pseudocysts. Gastrointest Endosc 1989;35:62-64.

8 MacErlean DP, Bryan PJ, Murphy JJ: Pancreatic pseudocyst: management by ultrasonographically guided aspiration. Gastrointest Radiol 1980;5:255-257.

-9 Adams DB, Harvey TS, Anderson MC: Percutaneous catheter drainage of pancreatic pseudocysts. Am Surg 1991;57:29-33.

10 Rogers BHG, Cicurel NJ, Seed RW: Transgastric needle aspiration of pancreatic pseudocyst through an endoscope. Gastrointest Endosc 1975;21:133-134.

11 Cremer M, Deviere J, Engelholm L: Endoscopic management of cysts and pseudocysts in chronic pancreatitis: long-term follow-up after 7 years of experience. Gastrointest Endosc 1989;35:1-9.

12 Sahel J, Bastid C, Pellat B, Schurgers P, Sarles H: Endoscopic cystoduodenostomy of cysts of chronic calcifying pancreatitis: a report of 20 cases. Pancreas 1987;2:447-453.

13 Liguory C, Lefebvre JF, Vitale GC: Endoscopic drainage of pancreatic pseudocysts. Can J Gastroenterol 1990;4:568-571.

14 Catalano MF, Geenen JE, Schmalz MJ, Johnson GK, Dean RS, Hogan WJ: Treatment of pancreatic pseudocysts with ductal communication by transpapillary pancreatic duct endoprosthesis. Gastrointest Endosc 1995;42:214218.

15 Kobayashi S, Ohara H, Nakazawa T, Sano H, Ando T, Aoki S, Okamoto T, Takada H, Hayashi K, Tanaka H, Kitajima Y, Mizuno S, Joh T: A case of chronic pancreatitis associated with infected psedocyst after endoscopic pancreatic stenting. Suizo 2006;21:89-94. 